\title{
Refractory Thymic Carcinoma
}

National Cancer Institute

\section{Source}

National Cancer Institute. Refractory Thymic Carcinoma. NCI Thesaurus. Code C148173.

Thymic carcinoma that does not respond to treatment. 